\title{
Research Regarding the Mechanical Properties of Some Biodegradable Polymeric Composites for Food Packaging Products
}

\author{
CONSTANTIN GHEORGHE OPRAN ${ }^{1 *}$, ELENA GROSU ${ }^{2}$, MARIUS ENACHESCU ${ }^{1}$ \\ University Politehnica of Bucharest, 313 Splaiul Independentei, 060042, Bucharest, Romania \\ ${ }_{2}^{2}$ SC ICPE Bistrita SA, 7 Parcului Str., 420035, Bistrita, Bistrita Nasaud, Romania
}

\begin{abstract}
Biodegradable polymers became one of the most important materials with large applicability, as they do not generate wastes after life cycle. An important application is food packaging fabricated by injection molding processing. In this paper, we present the investigation of the mechanical properties of some biodegradable polymers based on PLA composites obtained by melting processing and their morphology studied by SEM analyses, in comparison to polypropylene and neat PLA. We found out that tensile strength, elongation at break and Young modulus exhibit values appropriate to injection molding processing and they are very close related to crystalline or amorphous character of the materials.
\end{abstract}

Keywords: biodegradable polymers, biodegradable packaging, tensile properties of polymers, scanning electron microscope

Synthetic and natural polymers became the most important materials used in many fields of industrial, medical, building materials and agricultural applications [1-3]. In the late years, as following of agricultural performances and food industry development, appeared a serious problem of increase quantities of plastic waste packaging, their deposition and utiliy [4]. To overcome the problems related to environmental pollution, many researches performed new synthetic and natural biodegradable polymers, as well as new market entries of biodegradable packaging were registered.

Plastics are composed of carbon, nitrogen, oxygen, chlorine and bromine. Increased interest in biodegradability of polymers derives from capability of polymers to undergo biodegradable processes, by microbial attack on the polymeric backbone. Because the degradable polymers exhibit low physical-mechanical properties, difficulty in processing and high prices, in the recent years biodegradable polymers from renewable resources in natural abundance, become very interesting alternative. Biodegradable polymers can be classified in: naturally produced renewable polymers, synthetic polymers derived from renewable resources and synthetic polymers derived from petroleum-based resources.

As naturally renewable polymers there are the followings: cellulose, lignin, starch, chitin, collagen, gelatin, hyaluronic acid, dextran, heparin, xanthan, elastin, fibrin, pectin, and polyhydroxyalkanoates. Synthetic polymers derived from renewable resources are represented by polylactic acid (PLA). Among synthetic polymers derived from petroleum-based resources we can mention: Polycaprolactone (PCL), Polybutylene succinate, (PBS), Polybutylene adipate, (PBA), Polybutylene succinate-coadipates (PBSA), Polybutylenesadipate-co-butylene terephthalate (PBAT). Among the most used biodegradable polymers used in packaging we can mention biocellulose, chitin, starch, polyhydroxyalkanoates, polylactide, polybuthyrate adipate, polycaprolactone, collagen and other polypeptides. Besides them, many recipes were investigated and developed in order to improve physicalmechanical properties of the final product, bycompounding synthetic with natural polymers like polyvinyl alcohol with bacterial cellulose [5], or starch with polyester, or starch with PVA.
Degradation mechanisms of polymers can occur due to the enzyme action or can be caused by acids and peroxides produced by microorganisms (bacteria, yeasts, fungi, etc.), or micro-organisms digesting polymers $[6,7]$.

During biodegradation, are formed small size fragments of polymers that are mineralized by cells, together with gasses (e.g., $\mathrm{CO}_{2}, \mathrm{CH}_{4}, \mathrm{~N}_{2}, \mathrm{H}_{2}$ ), water, salts and minerals formation. Biodegradation process occurs depending on the polymer structure, the microorganisms involved and the environment conditions $[8,9]$.

The biodegradable polymers present the advantage of their usage, due to ability to degrade under microorganisms action, which leads to reducing quantity of plastics wastes deposed in the landfill. During degradation of plastics, enzymes act as catalysts while the hydrolysis constitutes the main mechanism occurring inside polymers materials [10]. The most biodegradable polymers are constituted from aliphatic and aromatic polyesters those physical properties are similar to petrochemical derived nonbiodegradable polymers.

In this research, we developed two biodegradable polymeric recipes based on polylactic acid (PLA) and polybutylene adipate-co-terephthalate (PBAT) in order to test physico-mechanical (tensile strength, elongation at break and Young modulus) and morphological properties. Also, in this research were selected materials from the category of polyolefins (polypropylene) as reference for non-biodegradable polymers, and neat polylactic acid (PLA) as reference for biodegradable polymers. Polymeric recipes presented in this work were developed to be used in the field of rigid biodegradable food packaging.

\section{Experimental part \\ Materials and method}

Materials used for the research were the followings:

-polypropylene TIPPLEN H 949 A (PP) from BASF with density $0.89 \mathrm{~g} / \mathrm{cm}^{3}$ and melt flow index (MFI) $45 \mathrm{~g} / 10 \mathrm{~min}$ at $230^{\circ} \mathrm{C} / 2.16 \mathrm{~kg}$;

-PBAT from Greenview Materials, with density $1.25 \mathrm{~g} /$ $\mathrm{cm}^{3}$, melting point $115^{\circ} \mathrm{C}$ and melt flow index $8 \mathrm{~g} / 10 \mathrm{~min}$; -polylactic acid (PLA) 3251D type from Nature Works LLC (Minnetonka, MN, USA), with density of $1.24 \mathrm{~g} / \mathrm{cm}^{3}$ and melt flow index of $35 \mathrm{~g} / 10 \mathrm{~min}\left(\right.$ at $\left.190^{\circ} \mathrm{C} / 2.16 \mathrm{~kg}\right)$; 
Polylactic acid (PLA) is a semi-crystalline, thermoplastic, aliphatic polyester and its monomer can be derived from annually renewable resources, with mechanical properties comparable to conventional petroleum-based plastics. PLA is an environmentally biodegradable polymer in conditions of appropriate temperature and moisture. His biodegradability involves chains hydrolyzing to oligomers with low molecular weight that are converted by microorganisms to carbon dioxide, water and humus [11]. PLA is mostly used for packaging and textile industry.

Polybutylene adipate-co-terephthalate (PBAT) is aliphatic-aromatic copolyester total biodegradable [12-13] PBAT due to the copolymerization of adipic acid and 1,4butanediol with butylenesterephthalate exhibithigher glass transition temperature like polymer - polybutylenes terephthalate. The mechanical properties and biodegradability of PBAT can be controlled by adjusting of the molar ratio of monomers in the copolymer [14]. PBAT was used in these experiments for toughening PLA in order to process the blend of polymers into rigid biodegradable containers.

Most bio-based polymers are used in the packaging industry to produce bottles, films, containers, cutlery, and trash bags. Also, biodegradable polymers are used to achieve packing food as fresh vegetables, fruits, salads, various bakery products. Another usage of bio based polymers is waste collection bags, carrier bags, mulchfilms. All these materials are accepted by the Food \& Drug Administration (FDA) to be used in food packaging.

Polymeric recipes developed and studied were: PP, PLA (neat PLA), ECV (compound formed by PLA 45\%wt and PBAT 55\%wt) and ECV-P (compound formed by PLA 60\% wt and PBAT 40\% wt). PLA and PBAT were melt blended using a twin-screw extruder and pelletized for injection molding. In addition to toughening PLA, PBAT increased the processability of PLA in extrusion by acting as a lubricant at low extrusion temperature.

\section{Preparation of polymeric samples}

Polymeric compound recipes ECV and ECV-P were achieved by melt blending in a Brabender Plastograph at a temperature of $180^{\circ} \mathrm{C}$, at fixed screw speed of $80 \mathrm{rpm}$.

Experimental specimens of PP, PLA, ECV and ECV-P were produced on injection press ENGEL Victory 120 within Manufacturing Engineering Department, Composites Products Laboratory from University Politehnica of Bucharest (fig. 1).

Technological parameters to process test specimens are:

- injection molding temperature at the nozzle: $190^{\circ} \mathrm{C}$ for PP; $160^{\circ} \mathrm{C}$ for PLA; $156^{\circ} \mathrm{C}$ for ECV; $150^{\circ} \mathrm{C}$ for ECV-P;

-injection pressure: 98 bar for PP; 96 bar for PLA; 94 bar for ECV; 94 bar for ECV-P;

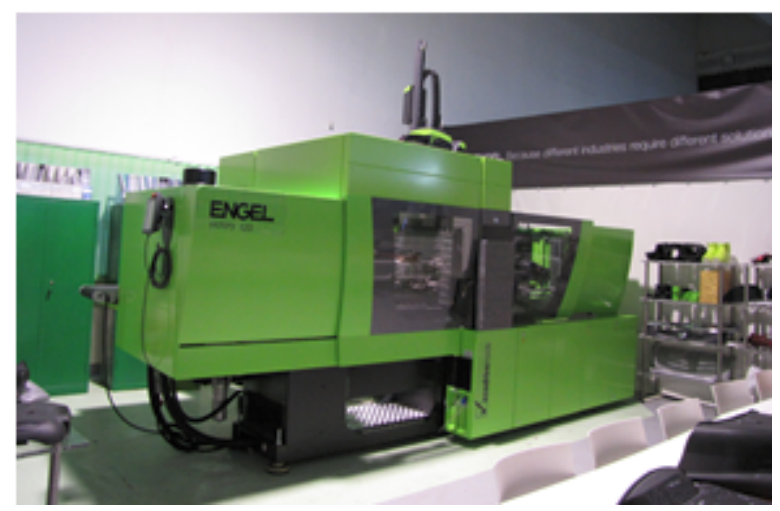

Fig. 1. Engel Victory injection molding machine -injection speed: $39 \mathrm{~mm} / \mathrm{sec}$ for PP; $37 \mathrm{~mm} / \mathrm{s}$ for PLA; $36 \mathrm{~mm} / \mathrm{sec}$ for ECV; $36 \mathrm{~mm} / \mathrm{sec}$ for ECV-P;

-injection cycle: 99 s for PP; 102 s for PLA; 95 s for ECV; $95 \mathrm{~s}$ for ECV-P.

\section{Density}

Density measurements for the samples, were carried out according to ISO 1183.

\section{Heat deflection temperature}

Heat deflection temperature (HDT) measurements were carried out by using specimens with $80 \mathrm{~mm} \times 10 \mathrm{~mm} \times 4$ $\mathrm{mm}$ dimensions according to EN ISO 75, Method A using a HDT/VICAT Softening Point Apparatus (CEAST Test Equipment). The tests were performed with a load of $10 \mathrm{~N}$ at a heating rate of $50^{\circ} \mathrm{C} / \mathrm{h}$. HDT is the temperature at which the specimen distortion increased to $0.32 \mathrm{~mm}$ during the heating process. Three test specimens were performed and the average value was reported.

\section{Tensile properties}

The tensile properties (tensile strength, elongation at break, the Young's modulus) were determined according to EN ISO 527-2 on specimens with thickness of $10 \mathrm{~mm}$. AZWICK Z020 TN PL test machine (fig. 2) operating at a crosshead speed of $10 \mathrm{~mm} \mathrm{~min}^{-1}$ was used for testing the specimens. At least ten samples were tested for each composition, and the average value was reported.

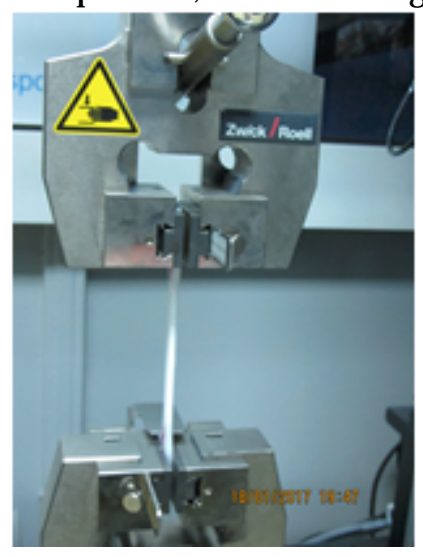

Fig. 2. ZWICK Z020 TN PL test machine

\section{Scanning electron microscope analyses}

Scanning electron microscope (SEM) micrographs were performed using Hitachi SU 8230 SEM equipped with EDX Oxford detector-analyzer.

\section{Results and discussions \\ Density}

Results obtained for samples density are presented in the Table 1. It can observe that PLA as reference material for biodegradable polymers exhibits the greatest density values. Also, PBAT that exhibits value of density $1.25 \mathrm{~g} /$ $\mathrm{cm}^{3}$ which lead to the total density of recipes ECV and ECV-P, close to PLA density value, as it can be observed in the table 1. Instead PP exhibits lower density due its to crystalline structure.

Table 1

VALUES OF DENSITIES FOR POLYMERIC SAMPLES STUDIED

\begin{tabular}{|l|c|}
\hline Recipe & Density $\left[\mathrm{g} / \mathrm{cm}^{3}\right]$ \\
\hline PP & $0.89 \pm 0.072$ \\
\hline PLA & $1.26 \pm 0.079$ \\
\hline ECV & $1.27 \pm 0.098$ \\
\hline ECV-P & $1.26 \pm 0.1$ \\
\hline
\end{tabular}




\section{Tensile properties}

PLA has a high tensile strength and Young modulus but because of its crystallinity and brittleness the elongation at break is very low. The ratio between PLA/PBAT in ECV recipes influenced as expected, the mechanical properties showing a significant decrease in the tensile strength and Young modulus for the ECV-P, while the elongation at break significantly increases. The elasticity modulus strongly decreases for both recipes ECV and ECV-P recipes compared to neat PLA.

The measured force - strain curves properties of the polymeric materials is presented in the figure 3 , while elongation at break of the samples is presented in the Fig. 4 and Young modulus is presented in the figure 5.

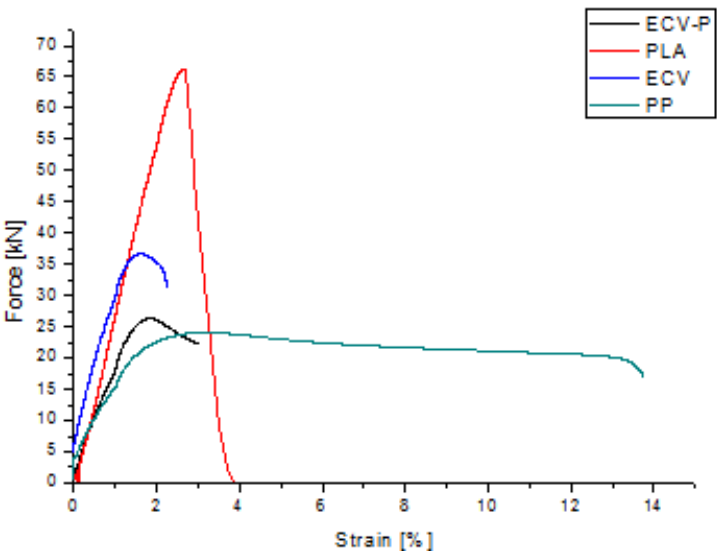

Fig. 3. The force-strain curves for experimental polymeric materials

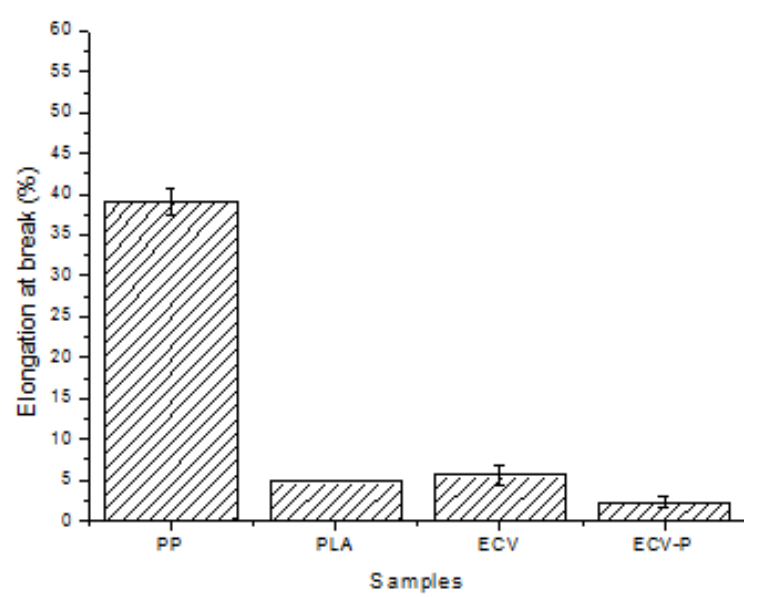

Fig.4. Elongation at break of the polymeric materials

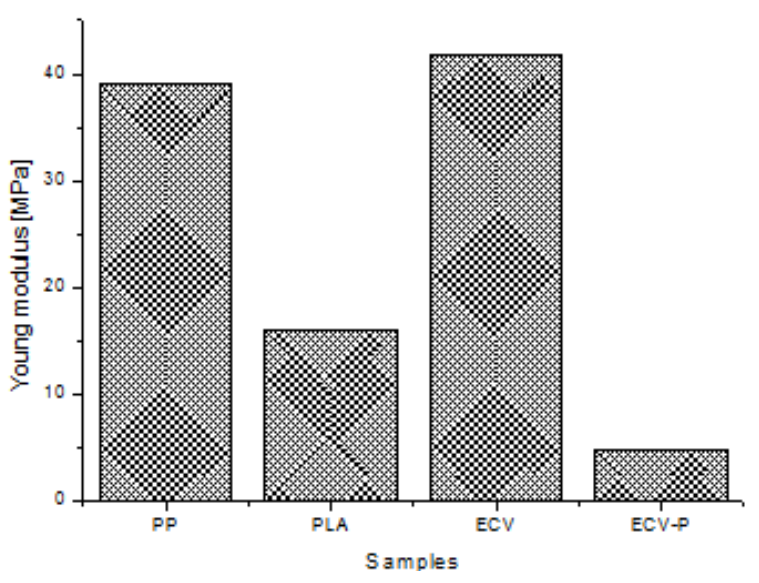

Fig. 5. Young modulus for polymeric materials
From the tensile fracture mechanism point of view the polymer materials presented in this work exhibit different types of stress-strain behavior due to their composition and individual structure/morphology. The force-strain curves offer a measure of the modulus in the initial slope. The two ECV and ECV-P recipes are compared with neat PP because present similar mechanical properties, wellknown processing technology at low cost as well as with neat PLA as promising material obtained from renewable resources, that exhibit also good mechanical properties. In this work, both PP and PLA were studied as sample control since they are representative for thermoplastic stable and biodegradable polymers, and also they are available on the plastics market.

As it can observe in the figure 3, materials based on PLA required high values of the force applied to samples for studying tensile properties. While PLA is a rigid material with semi-crystalline structure, PP has crystalline structure that gives a smaller resistance to an external force applied on the specimen. PLA force-strain curves exhibited the higher force $(68 \mathrm{kN})$ in comparison with PP that exhibited $27 \mathrm{kN}$. Because of the crystalline morphology, PP had a behavior more elastic during the experiment, in comparison with all materials studied, and showed the greatest value for the strain $13.89 \%$. ECV and ECV-P recipes are influenced by PLA content in the force-strain behavior. It can be observed that they required the usage of a standard force higher than PP samples but lower than PLA, because of the PBAT content. Also, the strain values were in the range of 2.2 to $3.8 \%$.

As resulted from the tensile experiments, PP exhibited the higher value of elongation at break due to crystalline structure, followed by ECV recipe with the smaller content of PLA. The values of elongation at break show that PLA is a rigid material, with a higher mechanical resistance to an external applied force. Also, the recipes with content of PLA exhibit lower elongation characteristics.

\section{Heat Deflection Temperature (HDT)}

The heat deflection temperature is presented in the Table 2. The higher value of HDT is obtained for PP due to crystalline structure. Itcan observe that in the ECV-P recipe, the higher content of PBAT lowers the value of HDT with about $10 \%$ in comparison with ECV and neatPLA. However both recipes exhibit increased thermal properties. Due to the good mechanical properties the PLA-based materials, could be used for rigid packaging applications.

Table 2

HDT (HEATING RATE 50 $\mathrm{C} / \mathrm{h}$, LOAD 10N)

\begin{tabular}{|l|l|}
\hline \multicolumn{1}{|c|}{ Recipe } & \multicolumn{1}{c|}{ HDT [ $\left.{ }^{\circ} \mathrm{C}\right]$} \\
\hline PP & $99 \pm 2$ \\
\hline PLA & $60 \pm 1$ \\
\hline ECV & $58 \pm 1$ \\
\hline ECV-PP & $51 \pm 1$ \\
\hline
\end{tabular}

\section{SEM results}

Scanning electron microscopy was performed to examining the tensile fracture surfaces and the interfacial compatibility of the polymers in the recipes. SEM micrographs examination in the figure 6 , reveals a good compatibility of components without distinct phase separation. Materials ECV and ECV-P exhibit similar morphologies, within pregnant evidence of two polymeric components PLA and PBAT. Also, ECV and ECV-P micrographs evidence the compatibility of extended polymeric chains of PLA and PBAT, indicating a more compact morphology. Due to increased content of PBAT in the recipe, the homogeneity seems to be better for ECV-P 


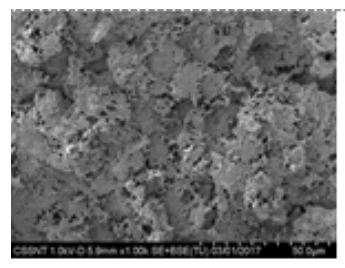

a) PP

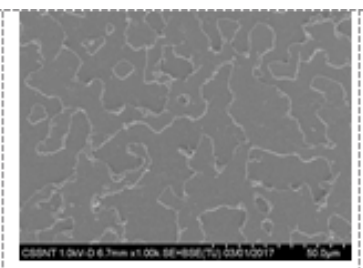

b) PLA

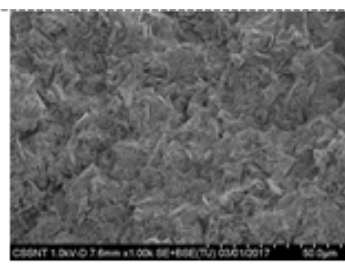

c) $\mathrm{ECV}$

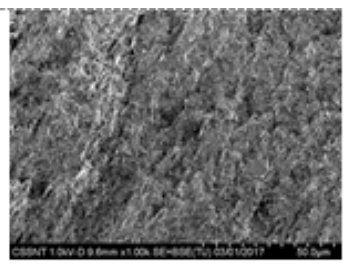

d) ECV-P
Fig. 6. SEM

micrography of the tensile fracture surface: a) PP, b) PLA, c) ECV, d) ECV recipe. The morphology is well connected the mechanical properties variation.

The fracture of the specimens reveals that there are exist no holes in the all materials after fracture. The polymer PP shows a small resistance to breakage, revealing small regions dislocated from the material during tensile experiment. Instead PLA exhibits an instant fracture of the material under external force applied, as a rigid material. ECV and ECV-P present similar behavior and the fracture of the specimens is obvious more intense in comparison with neat PLA.

\section{Conclusions}

In the present work, PLA and PBAT biodegradable polymers were considered in order to perform new materials with applications in food packaging. PLA and PBAT were compounded in melt processing via the twin screw extruder. Obtained ECV and ECV-P recipes, neatPLA and PP were injection molded to obtain sample specimen for physico-mechanical and morphological analyses. At this stage, it was demonstrated the mold injection processability of the proposed recipes. The polymeric recipes were studied in comparison with neat PLA and thermoplastic stable polymer polypropylene.

Based on the tensile tests it was observed that values of the external force applied were the highest for PLA based recipes. The greatest value of force is exhibited by neat PLA as material with semicrystalline structure. PP as polymer with crystalline structure, exhibited the smallest value of tensile properties. The recipes with PBAT in different percentages exhibit values of tensile strength lower than PLA due to the fact that PBAT has molecular weight lower than PLA. PP exhibits the greatest value for elongation at break because of the smallest molecular weight, in comparison with the recipes based on PLA.

HDT analysis offered valuable information regarding the thermal properties of the recipes. PP exhibits the greatest value for HDT, that means the PP material preserves its properties and integrity until $99^{\circ} \mathrm{C}$, instead of recipes based on PLA. ECV-P recipe with the smaller content of PBAT exhibits the lower HDT of $51^{\circ} \mathrm{C}$. Above this temperature the shape of the ECV-P is modified, suggesting that a rigid container from this material is not appropriate to be used to packing warm food. The same conditions are applied to ECV that exhibit HDT to $58^{\circ} \mathrm{C}$. PLA is closed to ECV as HDT properties. ECV and ECV-P exhibit uniform morphology due to the melt blending compatibility of the components. As result of mechanical, thermal and morphological properties analyses, itcan conclude that recipes presented in this study including PP, neat PLA, and PLA/PBAT, exhibited appropriated characteristics for food biodegradable packaging.

\section{References}

1. BENDING B., CHRISTISON K., RICCI J., EDIGER M.D., Macromolecules., 47, nr. 2, 2014, p. 800;

2. LANDEL R.F., NIELSEN L.E., Marcel Dekker, New York, 1994;

3. GROVES S.E., SANCHEZ R.J., LYON R.E., BROWN A.E., Composite Materials: Testing and Design, 11, 1993, p 162;

4. LEJA K., LEWANDOWICZ G., Polish J. of Environ. Stud., 19, nr. 2, 2010, p. 255;

5. JIPA I.M., et. al., Mater. Lett., 66, nr. 1, 2012, p. 125;

6.TSAO R., ANDERSON T.A., COATS J .R., J. Environ. Polym. Degrad., 1, 1993, p. 301;

7.WHITNEY P.J., SWAFFIELD C.H., GRAFFAM A.J ., Int Biodeterior, Biodegradation, 31, 1993, p. 179;

8. *** Handbook of Biodegradable Polymers, Rapra Technology Limited, Editor: Catia Bastioli.

9. PIELICHOWSKI K., NJ UGUNA J., Smithers Rapra Press, 2008;

10. MULLER R.J., KLEEBERG I., DECKER V., J. Biotechnol., 86, 2001, p. 87;

11. J IANG L., WOLCOTT M.P., ZHANG J., Biomacromolecules, 7, 2006, p. 199;

12. WITT U., et al., Chemosphere, 44, 2001, p. 289;

13. STAN, F., MUNTEANU, A.V, FETECAU, C., Mat. Plast., 48, no. 4, 2011, p. 1.

14. SOMEYA Y., KONDO N., SHIBATA M., J. Appl. Polym. Sci., 106, 2007, p. 730.

Manuscript received: 15.09 .2018 